\title{
Alternating Copolymerization of Acetylenic Donor and Acceptor Monomers
}

\author{
Junji Furukawa, Eiichi Kobayashi, and Tadahiro WaKuI* \\ Department of Industrial Chemistry, Science University of Tokyo, \\ 2641, Higashikameyama, Yamazaki, Noda 278, Japan. \\ * Research Laboratory, Maruzen Oil Co., \\ Satte, Saitama 340-01, Japan.
}

(Received July 25, 1979)

\begin{abstract}
Copolymerization of acetylenic donor and acceptor monomers catalyzed by ethylaluminum chloride with or without transition metal compounds was investigated. The addition of a transition metal compound increases the yield and the molecular weight of a copolymer, but has little effect on the copolymer composition. The resulting copolymers were each found to possess an almost $1: 1$ composition, but a relatively low molecular weight.
\end{abstract}

KEY WORDS Alternating Copolymerization / Acetylenic Donor Monomer / Acetylenic Acceptor Monomer / Ethylaluminum Chloride / Transition Metal Compound / Phenylacetylene / Acetylene / Methyl Propiolate / Cyanoacetylene / Dimethyl Acetylenedicarboxylate /

The polymerization of acetylene $e^{1.2}$ or substituted acetylene $^{3-5}$ has received considerable attention, and many available methods for achieving this polymerization have been proposed. ${ }^{6}$ However, no investigation has been reported for the alternating copolymerization of acetylenic donor and acceptor monomers, though there have been a few reports on the copolymerization of acetylenic monomers. ${ }^{7,8}$ It may be that polymer chains containing both electron donor and acceptor substituents show intra- and inter-chain interaction. The synthesis of these copolymers belongs to a quite new and interesting research field.
This paper deals with the copolymerization of acetylenic donor and acceptor monomers by use of ethylaluminum chloride as a complexing agent with or without transition metal compounds as a catalyst.

\section{EXPERIMENTAL}

\section{Materials}

Commercial phenylacetylene (PA), methyl propiolate (MP), dimethylacetylenedicarboxylate (DAD) and toluene used as a solvent were distilled over a molecular sieve $3 \mathrm{~A}$ under a nitrogen atmosphere just before use. Commercially available acet-

$$
\begin{array}{cc}
\mathrm{HC} \equiv \mathrm{C}-\mathrm{X}+\mathrm{Y} \mathrm{Y}_{1}-\mathrm{C} \equiv \mathrm{C}-\mathrm{Y}_{2} \longrightarrow+\begin{array}{r}
(\mathrm{HC}=\mathrm{C}-\mathrm{C}=\mathrm{C})_{n} \\
\mathrm{X} \mathrm{Y}_{1} \mathrm{Y}_{2}
\end{array} \\
\mathrm{AC}, \mathrm{X}: \mathrm{H} \quad \mathrm{MP}, \mathrm{Y}_{1}: \mathrm{H}, \quad \mathrm{Y}_{2}: \mathrm{COOCH}_{3} \\
\mathrm{PA}, \mathrm{X}: \mathrm{Ph} \quad \mathrm{CA}, \mathrm{Y}_{1}: \mathrm{H}, \quad \mathrm{Y}_{2}: \mathrm{CN} \\
\quad \mathrm{DAD}, \mathrm{Y}_{1}: \mathrm{COOCH}_{3}, \quad \mathrm{Y}_{2}: \mathrm{COOCH}_{3}
\end{array}
$$

ylene $(\mathrm{AC})$ was purified in the gaseous state in the usual way. ${ }^{9}$ Cyanoacetylene (CA) was prepared by the method of Moureu and Bongrand. ${ }^{10}$ Methyl propiolate was converted to propiolamide and then to cyanoacetylene by dehydration. Ethylaluminum dichloride and triethylaluminum were distilled in vacuo before use. Transition metal compounds of chemically pure grade were used without further purification. 


\section{Polymerization}

The procedure for polymerization was similar to that described for the copolymerization of acetylenic monomers and 1,3-diene. ${ }^{9}$

The isolation of the copolymers was carried out mainly by the following procedure. After polymerization, the reaction mixture was poured into a large excess of methanol containing a small amount of $N$ phenyl- $\beta$-naphthylamine as a stabilizer for the polymer. The solid polymer was separated and washed with methanol (polymer 1). The residual methanol solution was concentrated, and then water was added and the resulting solution was extracted several times with $\mathrm{CHCl}_{3}$. The $\mathrm{CHCl}_{3}$ layer was washed with $6 \mathrm{~N}$ aqueous hydrochloric acid solution and then with water, dried over $\mathrm{MgSO}_{4}$ and evapolated to about one tenth of its volume. The residual $\mathrm{CHCl}_{3}$ solution was poured into a large excess of hexane. The polymer coagulated was purified by reprecipitation from the $\mathrm{CHCl}_{3}$ solution into hexane, followed by drying in vacuo (polymer 2).

In the case of the copolymerization of acetylene and the acceptor monomer, polymerization was carried out by bubbling the acetylene gas into the toluene solution of the catalyst and the comonomer. The isolation of polymer was carried out in a manner similar to the above procedure.

\section{Characterization}

The copolymer composition was estimated from the elementary analysis and NMR. spectrum. The NMR spectrum was measured by a $60-\mathrm{MHz}$ JNMPMX60 NMR spectrometer by using $\mathrm{CDCl}_{3}$. The IR spectrum was taken with Hitachi-EPI-S2 type spectrometer. Molecular weights were determined by a Hitachi Parkin-Elmer 115 vapor pressure osmometer, using benzene as the solvent. UV spectra were recorded on a JOL-UVIDEC-505 spectrophotometer with $\mathrm{CCl}_{4}$ as the solvent.

\section{RESULTS AND DISCUSSION}

\section{Polymerization of PA and Acceptor Monomers}

The copolymerization of phenylacetylene (PA) and methyl propiolate (MP) or dimethyl acetylenedicarboxylate (DAD) was investigated using a catalyst containing ethylaluminum chloride added to the acceptor monomer or by a radical initiator. As shown in Table $I$, ethylaluminum dichloride $\left(\mathrm{EtAlCl}_{2}\right)$ was the best complexing agent, giving an orange or yellow colored alternating copolymer, whereas triethylaluminum was scarcely active. This order of activity agreed with the order of acidity of ethylaluminum chlorides.

On the other hand, the free radical copolymeri-

Table I. Copolymerization of PA and MP or DAD at $20^{\circ} \mathrm{C}^{\mathrm{e}}$

\begin{tabular}{|c|c|c|c|c|c|c|c|c|}
\hline \multirow{2}{*}{$\begin{array}{l}{[\mathrm{PA}]} \\
\mathrm{mmol}\end{array}$} & \multicolumn{2}{|c|}{$\begin{array}{l}\text { Acceptor } \\
\text { monomer }\end{array}$} & \multirow{2}{*}{$\frac{[\mathrm{A}] /[\mathrm{PA}]}{\mathrm{mol} \%}$} & \multicolumn{2}{|c|}{ Catalyst } & \multirow{2}{*}{$\frac{\begin{array}{c}\text { Polymerization } \\
\text { time }\end{array}}{\mathrm{h}}$} & \multirow{2}{*}{$\begin{array}{c}\text { Yield } \\
\% \\
\end{array}$} & \multirow{2}{*}{$\begin{array}{c}\begin{array}{c}{[\mathrm{A}]} \\
\text { in polymer } 2\end{array} \\
\mathrm{~mol} \%\end{array}$} \\
\hline & {$[\mathrm{A}]$} & $\mathrm{mmol}$ & & & $\mathrm{mmol}$ & & & \\
\hline 9.1 & MP & 9.1 & 50 & $\mathrm{Et}_{3} \mathrm{Al}$ & 6.8 & 20 & Trace & - \\
\hline 9.1 & MP & 9.1 & 50 & $\mathrm{EtAlCl}_{2}$ & 6.8 & 20 & 59.3 & $53.6^{\mathrm{c}}$ \\
\hline 9.1 & DAD & 9.1 & 50 & $\mathrm{EtAlCl}_{2}$ & 6.8 & 20 & 44.5 & 54.7 \\
\hline 9.1 & MP & 9.1 & 50 & $\mathrm{BPO}^{\mathrm{a}}$ & & 55 & 7.0 & $69.3^{\mathrm{d}}$ \\
\hline 9.1 & DAD & 9.1 & 50 & $\mathrm{BPO}^{\mathrm{a}}$ & & 55 & 16.0 & 64.1 \\
\hline 9.1 & DAD & 9.1 & 50 & $\mathrm{AIBN}^{\mathrm{a}}$ & & 57 & 22.6 & 68.1 \\
\hline 9.1 & MP & 2.3 & 20.2 & EtAlCl ${ }_{2}$ & 2.0 & 2 & $8.8^{\mathrm{b}}$ & 32.5 \\
\hline 9.1 & MP & 3.4 & 27.2 & $\mathrm{EtAlCl}_{2}$ & 3.0 & 4 & $16.3^{\mathrm{b}}$ & 38.6 \\
\hline 6.4 & MP & 5.7 & 47.1 & $\mathrm{EtAlCl}_{2}$ & 4.5 & 7 & $4.5^{\mathrm{b}}$ & 48.3 \\
\hline 2.7 & MP & 6.8 & 71.6 & $\mathrm{EtAlCl}_{2}$ & 5.5 & 7 & $11.2^{\mathrm{b}}$ & 55.6 \\
\hline 1.8 & MP & 9.1 & 83.5 & $\mathrm{EtAlCl}_{2}$ & 6.8 & 3 & $20.3^{\mathrm{b}}$ & 51.4 \\
\hline
\end{tabular}

a Polymerization temp, $70^{\circ} \mathrm{C} .2 .0 \mathrm{wt} \%$ of BPO or AIBN was used.

b Calculated based on MP.

c $M_{n}=750$.

d $M_{n}=630$.

e Solvent, toluene, $5 \mathrm{ml}$. 
zation of PA and MP or DAD by benzoyl peroxide (BPO) or azobisisobutyronitrile (AIBN) at $70^{\circ} \mathrm{C}$ also produces a copolymer. However, the yield and molecular weight were lower than those of the polymerization in the presence of $\mathrm{EtAlCl}_{2}$, and MPor DAD-rich copolymer was obtained. Table I also shows that the copolymer composition is little influenced by the feed monomer ratio even though the PA-rich copolymer is obtainable from the PAexcess monomer in the feed. The amount of $\mathrm{EtAlCl}_{2}$ was maintained almost constant against the MP.

In the $\mathrm{EtAlCl}_{2}$-transition metal compound system, PA reacts with an acetylenic acceptor monomer such as MP, CA or DAD to give the copolymer. In some cases methanol-insoluble polymers containing high PA unit were produced. The effect of a catalyst such as $\mathrm{WCl}_{6}$ on copolymerization is shown in Table II. In the presence of a lesser amount of $\mathrm{EtAlCl}_{2}$ added to MP, the copolymerization proceeds more effectively by the addition of small amount of $\mathrm{WCl}_{6}$ than without it and rather high molecular weight of polymers is obtained. Other transition metal compounds such as $\mathrm{MoCl}_{5}, \mathrm{Mn}(\mathrm{acac})_{3}$ and $\mathrm{Co}(\mathrm{dmg})_{2}$ accelerate the polymerization effectively, but they have little effect on the copolymer composition as illustrated in Table II. Similar results were obtained in the copolymerization of the PA and CA systems or PA and DAD systems. The elementary analysis or NMR spectrum of the resulting copolymers showed that they were of almost $1: 1$ in composition.

The NMR spectra of the copolymers of PA and acceptor monomers measured in $\mathrm{CDCl}_{3}$ show a simple, but broad spectrum pattern composed of two or three peaks, where the peak at $\delta 6.3-8.0$ in the lowest magnetic field is assigned to the aromatic and olefin protons and the signal at $\delta 3.0-4.1$ is due to

Table II. Copolymerization of PA and acetylenic acceptor monomers by transition metal catalysts at $20^{\circ} \mathrm{C}^{\mathrm{f}}$

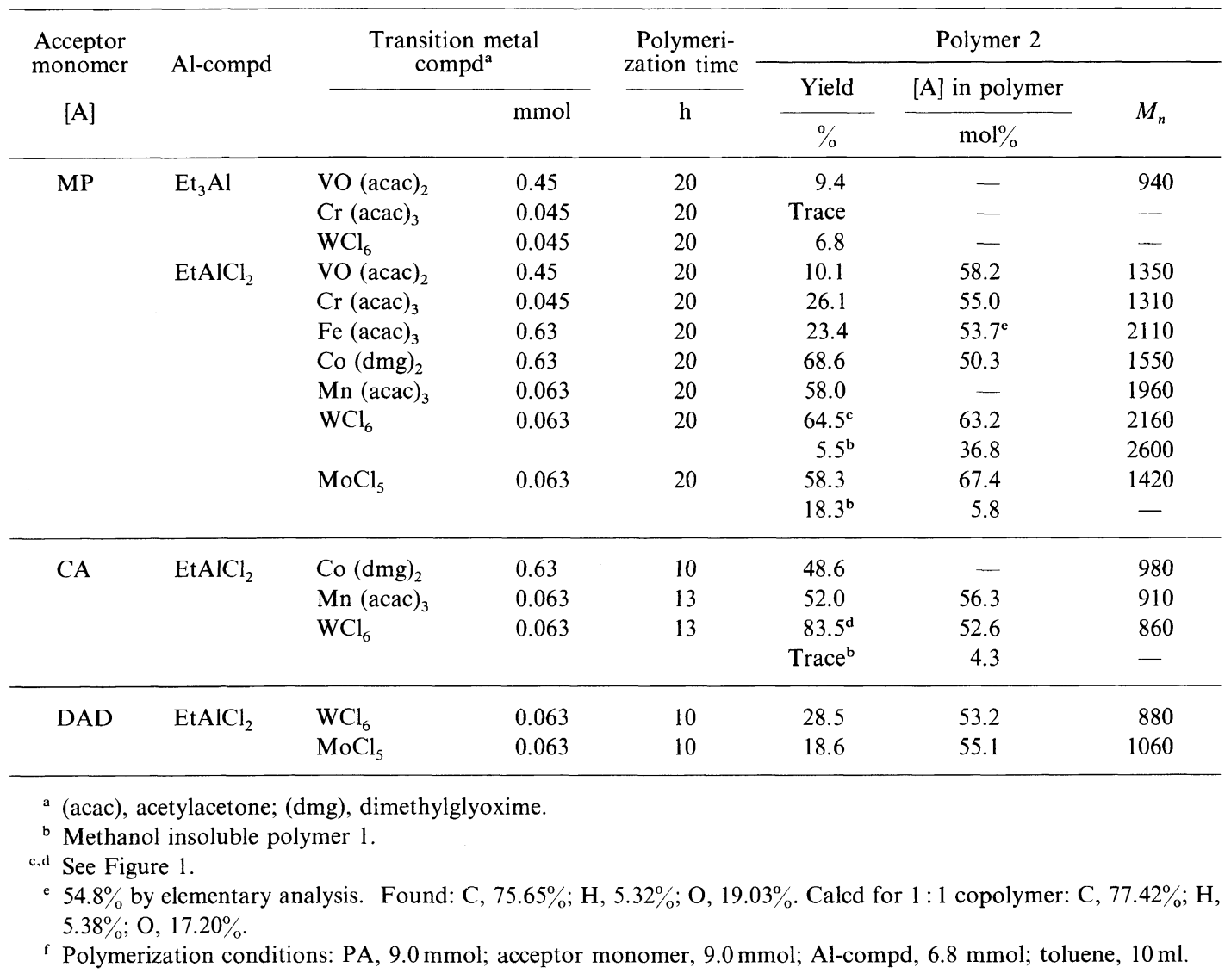


the methyl protons of the ester or diester. The irifrared spectra of the copolymers of PA and MP or $\mathrm{CA}$ determined in the $\mathrm{KBr}$ disc are illustrated in Figure 1, where the peak of the carbonyl group of ester is observed at $1700 \mathrm{~cm}^{-1}$, the absorption due to the $\mathrm{C}=\mathrm{C}$ bond at $1585 \mathrm{~cm}^{-1}$ and the phenyl group absorption at 700 and $755 \mathrm{~cm}^{-1}$. Similar spectral data were obtained for the PA-DAD copolymer, indicating the assigned structure. The IR spectrum $(\mathrm{KBr})$ showed absorptions at $1720\left(\mathrm{COOCH}_{3}\right), 700$ and $755(\mathrm{Ph})$, and $1590(\mathrm{C}=\mathrm{C}) \mathrm{cm}^{-1}$. The IR spectrum $(\mathrm{KBr})$ of the $\mathrm{PA}-\mathrm{CA}$ copolymer showed the absorption characteristic of a cyano group at $2180 \mathrm{~cm}^{-1}$, a phenyl group absorption at 695 and $750 \mathrm{~cm}^{-1}$, and an absorption due to the $\mathrm{C}=\mathrm{C}$ bond at $1580 \mathrm{~cm}^{-1}$.
Masuda et al. or Ehrlich et al. assumed the structure of conjugated chain of poly(phenylacetylene) to be the cis-form, from the week absorption at $770 \mathrm{~cm}^{-111}$ and from the exothermal order-disorder transition in the thermal analysis. ${ }^{12.13}$ However, these were not clear with our present system.

The molecular weights of these polymers were low. However, polyacetylene obtained by the polymerization of acetylene with Ziegler type catalysts probably was of high molecular weight. These results might show that a bulky substituent on the acetylenic carbon atom is sterically unfavorable in the propagation step of the alternating copolymerization and that the substituted acetylene end group is vulnerable to hydrogen transfer.
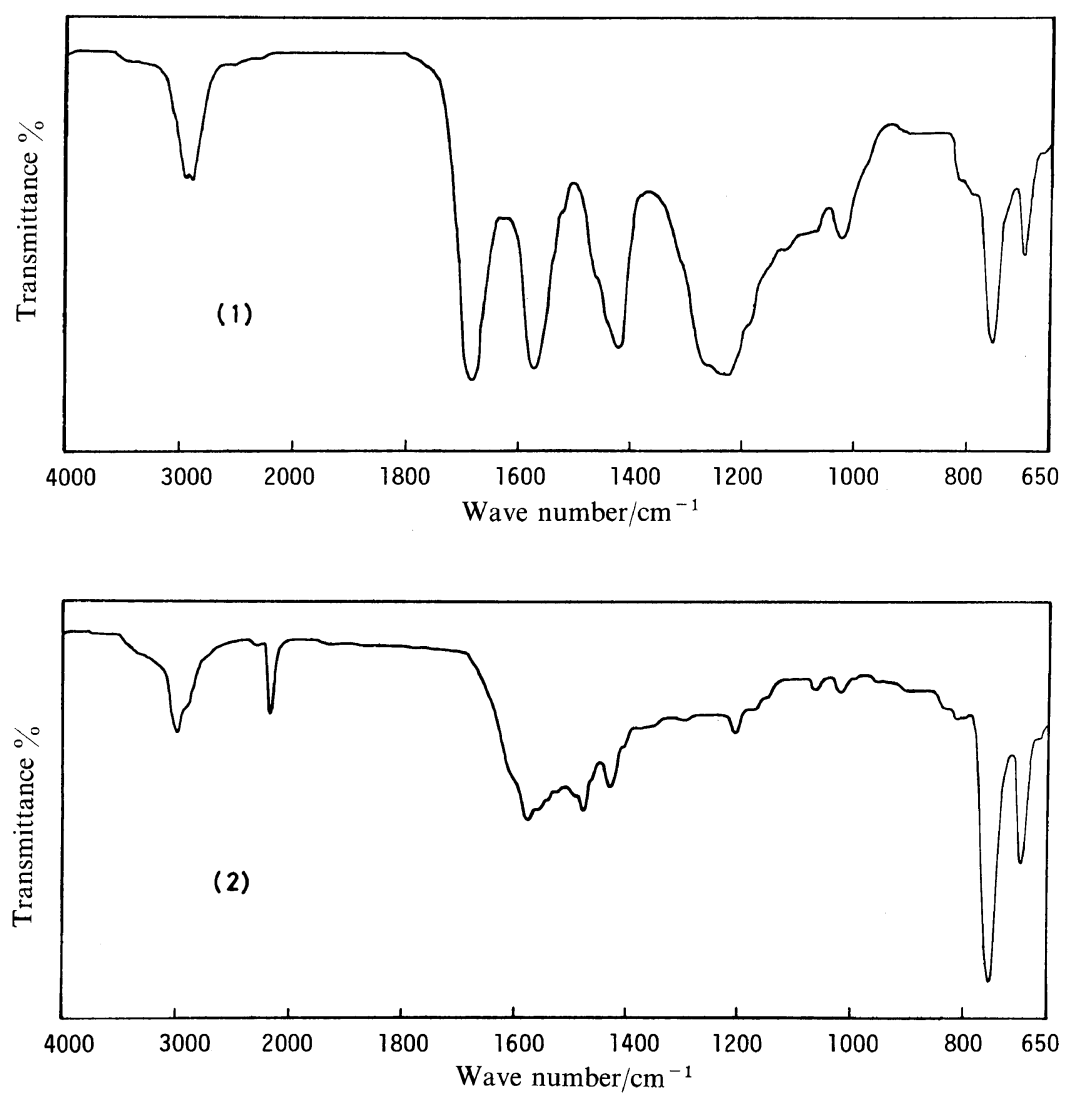

Figure 1. Infrared spectra of polymer.

(1) PA-MP. See c in Table I.

(2) PA-CA. See d in Table I. 
The content of the acceptor monomer in a methanol-insoluble polymer (polymer 1) was fairly lower than that of the monomer in the feed. On the other hand, the homopolymerization of PA may occur simultaneously. It is necessary that $\mathrm{EtAlCl}_{2}$ is mixed and complexed with the acceptor monomer prior to mixing with $\mathrm{PA}$, since $\mathrm{PA}$ is reactive against $\mathrm{EtAlCl}_{2}$.

All of the resulting copolymers were generally orange or yellow in color. Low molecular weight of copolymers was brownish or pale yellow. These polymers were soluble in $\mathrm{CHCl}_{3}$, benzene, acetone or many other organic solvents, and were insoluble in hexane or cyclohexane.

Figure 2 shows the electronic spectra of the intermediate complex of the PA-MA copolymer with iodine at $25^{\circ} \mathrm{C}$. The spectra were deduced from the spectra of the PA-MA copolymer, using same concentration of PA-MP copolymer as the reference. The iodine complex shows two absorptions at $300 \mathrm{~nm}$ and $350 \mathrm{~nm}$. These spectra were a little different from those of the intermediate complexes of styrene and iodine. Maximum wavelengths of these absorptions were relatively short becuase of the lack of or shortness in conjugation, compared with polyacetylene. $^{14}$

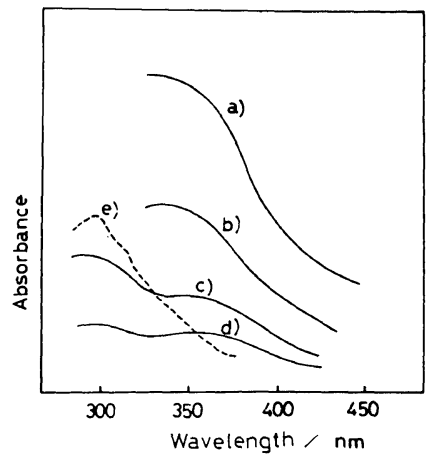

Figure 2. Electronic spectra of the intermediate complex of the PA-MP copolymer with iodine in $\mathrm{CCl}_{4}$ at $25^{\circ} \mathrm{C}$.

Polymer concentration: a), $2.58 \times 10^{-3} \mathrm{moll}^{-1}$; b), $\left.\left.1.29 \times 10^{-3} \mathrm{moll}^{-1} ; \mathrm{c}\right), 7.74 \times 10^{-4} \mathrm{moll}^{-1} ; \mathrm{d}\right)$, $2.58 \times 10^{-4} \mathrm{moll}^{-1}$. $\mathrm{I}_{2}$ concentration, $2.85 \times 10^{-4}$ moll $\left.\mathrm{l}^{-1} . \mathrm{e}\right)$, styrene- $\mathrm{I}_{2}$.

Polymerization of Acetylene and Acceptor Monomers

In the $\mathrm{EtAlCl}_{2}$-transition metal compounds system, acetylene (AC) reacts with acetylenic acceptor monomer such as MP or DAD to give copolymers. These results are listed in Table III. It was found that $\mathrm{WCl}_{6}$ or $\mathrm{MoCl}_{5}$ accelerates polymerization more effectively than $\mathrm{Mn}, \mathrm{Co}$ or $\mathrm{Cr}$ compounds. In the

Table III. Copolymerization of AC and MP or DAD at $20^{\circ} \mathrm{C}$ for $6 \mathrm{~h}^{\mathrm{d}}$

\begin{tabular}{|c|c|c|c|c|c|c|c|c|c|}
\hline \multirow{2}{*}{\multicolumn{2}{|c|}{$\begin{array}{l}\text { Acceptor } \\
\text { monomer }\end{array}$}} & \multirow{2}{*}{\multicolumn{2}{|c|}{$\begin{array}{c}\text { Transition metal } \\
\text { compd }\end{array}$}} & \multicolumn{3}{|c|}{ Polymer 2} & \multicolumn{3}{|c|}{ Polymer 1} \\
\hline & & & & \multirow{3}{*}{$\frac{\text { Yield }}{\%}$} & \multirow{3}{*}{$\begin{array}{c}\begin{array}{c}{[\mathrm{A}] \text { in }} \\
\text { polymer }\end{array} \\
\mathrm{mol} \%\end{array}$} & \multirow{3}{*}{$M_{n}$} & \multirow{3}{*}{$\frac{\text { Yield }}{\%}$} & \multirow{3}{*}{$\frac{\begin{array}{c}{[\mathrm{A}] \text { in }} \\
\text { polymer }\end{array}}{\mathrm{mol}^{\mathrm{o}} \%}$} & \multirow{3}{*}{$M_{n}$} \\
\hline$[\mathrm{A}]$ & $\mathrm{mmol}$ & & $\mathrm{mmol}$ & & & & & & \\
\hline & & & & & & & & & \\
\hline \multirow[t]{5}{*}{ MP } & 9.0 & $\mathrm{Mn}(\mathrm{acac})_{3}$ & 0.063 & 32.0 & - & Yellow oil & & & \\
\hline & 9.0 & $\mathrm{Co}(\mathrm{dmg})_{2}$ & 0.63 & 15.6 & - & Yellow oil & & & \\
\hline & 9.0 & $\mathrm{Cr}(\mathrm{acac})_{3}$ & 0.063 & 7.2 & - & Yellow oil & & & \\
\hline & 9.0 & $\mathrm{WCl}_{6}$ & 0.063 & 18.0 & $59.5^{\mathrm{a}}$ & 1200 & 8.3 & $50.3^{b}$ & - \\
\hline & 9.0 & $\mathrm{MoCl}_{5}$ & 0.063 & 10.4 & 53.6 & 1080 & 5.8 & 5.0 & Insoluble \\
\hline \multirow[t]{3}{*}{ DAD } & 9.0 & $\mathrm{Co}(\mathrm{dmg})_{2}$ & 0.63 & 12.1 & - & Yellow oil & & & \\
\hline & 9.0 & $\mathrm{WCl}_{6}$ & 0.063 & 14.6 & $56.1^{\mathrm{c}}$ & 830 & 4.5 & 0 & Insoluble \\
\hline & 9.0 & $\mathrm{MoCl}_{5}$ & 0.063 & 8.7 & 72.3 & - & 6.8 & 0 & Insoluble \\
\hline
\end{tabular}

a See Figure 3. $60.7 \%$ by elementary analysis. Found: C, $63.01 \% ; \mathrm{H}, 5.25 \%$; O, 31.74\%. Calcd for $1: 1$ copolymer: $\mathrm{C}$, $65.46 \% ; \mathrm{H}, 5.45 \% ; \mathrm{O}, 29.09 \%$.

b See Figure 3.

c $58.9 \%$ by elementary analysis. Found: $\mathrm{C}, 55.42 \%$; H, 4.62\%; O, 39.96\%. Calcd for 1 : 1 copolymer: $\mathrm{C}, 57.15 \%$; $\mathrm{H}$, $4.76 \% ; \mathrm{O}, 38.09 \%$.

d Polymerization conditions: AC, 5-7 $\mathrm{ml} \mathrm{min}^{-1}$ : $\mathrm{EtAlCl}_{2}, 6.8 \mathrm{mmol}$; toluene, $15 \mathrm{ml}$. 
case of polymerization by $\mathrm{MoCl}_{5}$ as the catalyst, the homopolymerization of acetylene occurred concurrently and little copolymer was produced.

The NMR spectra of AC-MP or AC-DAD copolymers show a peak at $\delta 6.3-8.0$ assignable to the olefin protons, and a signal at $\delta 3.4-4.3$ that is due to the methyl protons of the ester or diester.

The IR spectra $(\mathrm{KBr})$ of the copolymers of $\mathrm{AC}$ and MP or DAD showed the absorption characteristics of a carbonyl group of ester at $1700 \mathrm{~cm}^{-1}$, and an absorption due to the trans-form of $\mathrm{CH}=\mathrm{CH}$ bond at $990 \mathrm{~cm}^{-1}$ for polymer 1 , and then showed an absorption due to the cis-form of $\mathrm{CH}=\mathrm{CH}$ bond at $750 \mathrm{~cm}^{-1}$ for polymer 2 (Figure 3 ).

In the copolymerization of donor and acceptor monomers, aluminum compounds act both as complexing agents with acceptor monomers and as initiators. ${ }^{15}$ The alternating copolymerization proceeds by the way of the polymerization of a ternary complex among donor-acceptor monomer-aluminum compound. ${ }^{15}$ Some promotors such as $\mathrm{VOCl}_{3}$ and $\mathrm{TiCl}_{4}$ are useful for alternating copolymerization. ${ }^{15}$ However, at the present, the copolymerization mechanism of the acetylenic donor and acceptor monomers is not clear, but the coordination of the monomers with catalyst may play an important role in controlling, the copolymerizability of monomers.

\section{REFERENCES}

1. M. Hatano, S. Kambara, and S. Okamoto, J. Polym. Sci., 51, S 26 (1961).

2. H. Shirakawa, T. Ito, and S. Ikeda, Polym. J., 4, 460 (1973).

3. T. Masuda, T. Kim-Quan, and T. Higashimura, Polym. J., 10, 269 (1978).

4. Cr. Simionescu, S. Dumitrescu, and V. Percec, Polym. J., 8, 139 (1976).

5. H Noguchi and S. Kambara, J. Polym. Sci., B, 1, 553 (1963).

6. as a review, M. G. Chanser, Usp. Khim., 45, 695 (1976).

7. A. G. Hankin and A. M. North, Trans. Faraday Soc., 63, 1525 (1967).

8. L. S. Meriwether, E. C. Colthup, G. W. Kennerly, and R. N. Reusch, J. Org. Chem., 26, 5155 (1961).

9. J. Furukawa, E. Kobayashi, and T. Kawagoe, $J$. Polym. Sci., Polym. Chem. Ed., 14, 1609 (1978).

10. C. H. Moureu and J. Ch. Bongrand, Ann. Chim., 14, 47 (1920).

11. T. Masuda, T. Ohtori, T. Mouri, and T. Higashimura, Polym. Prepr., Jpn., 27, 773 (1978).

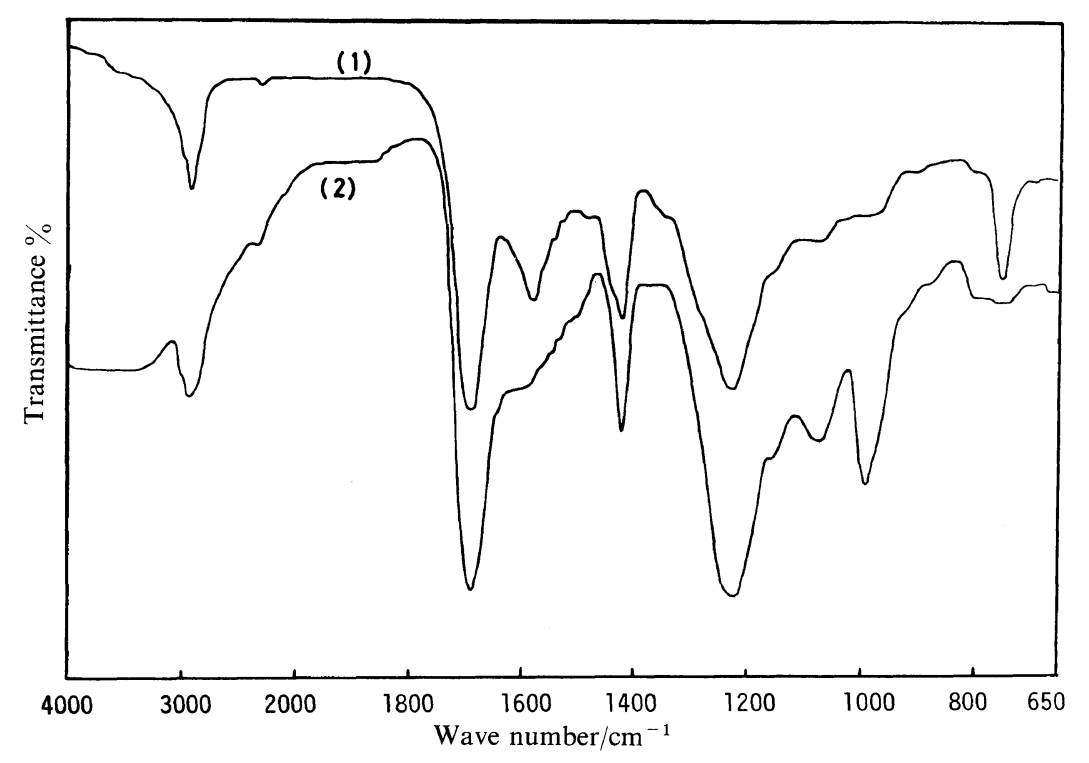

Figure 3. Infrared spectra of polymer.

(1) AC-MP. See a in Table III. Microstructure of polymer 2 is cis-form.

(2) AC-MP. See b in Table III. Microstructure of polymer 1 is trans-form. 


\section{Alternating Copolymerization of Acetylenic Donor and Acceptor Monomers}

12. P. Ehrlich, J. Macromol. Sci.,Phys., B 2, 153 (1968).

13. G. M. Holob, P. Ehrlich, and R. D. Allendoerfer, Macromolecules, 5, 569 (1972).

14. H. Shirakawa, T. Sakaki, and S. Ikeda, Chem. Lett.,
1113 (1978).

15. J. Furukawa and E. Kobayashi, Rubber Chem. Technol, 51, 600 (1978). 